BASINDO : Jurnal Kajian Bahasa, Sastra Indonesia, dan Pembelajarannya

Volume 2 Nomor 1, 2018

Journal homepage : http://journal2.um.ac.id/index.php/basindo

\title{
RELASI MUATAN ILOKUTIF DA NKESANTUNAN BERBAHASA PADA WACANA DISKUSI
}

\author{
Ine Erna Andriana* \\ Universitas Negeri Surabaya, Indonesia
}

\begin{tabular}{|c|c|}
\hline A R T I C LE I N F O & A B S T R ACT \\
\hline $\begin{array}{l}\text { Keyword: } \\
\text { muatan ilokutif, } \\
\text { kesantunan berbahasa, } \\
\text { relasi, } \\
\text { wacana diskusi siswa kelas } \\
\text { VII }\end{array}$ & $\begin{array}{l}\text { Penelitian ini bertujuan mendeskripsikan muatan ilokutif, kesantunan berbahasa, dan } \\
\text { relasi muatan ilokutif dan kesantunan berbahasa pada wacana diskusi siswa kelas VII. } \\
\text { Penelitian ini menggunakan metode kualitatif deskriptif. Hasil penelitian menunjukkan } \\
\text { bahwa (1) muatan ilokutif pada wacana diskusi siswa terdiri atasmuatan ilokutif } \\
\text { ekspresif, direktif, representatif,komisif,dandeklaratif;(2)wacana diskusi siswa prinsip } \\
\text { kesantunan berbahasa maksim kearifan, kedermawanan, kesepakatan, pujian, } \\
\text { kerendahhatian, dan simpati daripada pelanggaran, dan (3) Relasi muatan ilokutif dan } \\
\text { kesantunan berbahasa teraktualisasi pada ekspresif santun, direktif santun, representatif } \\
\text { santun, dan komisif santun. }\end{array}$ \\
\hline
\end{tabular}

\section{PENDAHULUAN}

$\begin{array}{ccc}\text { Clark dan Clark(1977:277) } & \text { mengatakan bahwa saat bertutur, penutur harus memutuskan pada } \\ \text { muatan proporsional, } & \text { muatan ilokutif, dan struktur tematik dari apa yang ingin mereka }\end{array}$ katakan, kemudian memilih kalimat untuk menyesuaikan. Berdasarkan ketiga perencanaan kalimat tersebut,ujaran yang terdapat dalam tuturan penting untuk diketahui sehingga peneliti lebih memfokuskan pada penelitian tentang muatan ilokutif. Menurut Clark dan Clark (1977:239) dalam membuat kalimat, penutur harus memutuskan muatan ilokutif apa untuk membuat lawan tutur melakukan tindakan tertentu. Penutur memiliki dua masalah yang perlu dipecahkan. Pertama, tindak tutur apa yang ingin dipakai untuk menyampaikan kalimat, secara langsung atau secara tidak langsung. Kedua, dalam bentuk bagaimana kalimat harus diungkapkan, secara representatif, direktif, komisif, ekspresif, ataudeklaratif.

Muatan ilokutif berhubungan dengan kesantunan berbahasa seseorang. Ketika penutur telah memutuskan tindak tutur yang akan digunakan, ia juga harus memutuskan bentuk yang harus dipilih. Alasan penutur memilih muatanilokutif yang akan digunakan adalah faktor efisiensi dan interpretasi. Penutur menyampaikan kalimatnya dengan cara langsung atau tidak langsung, dalam kalimat Pengucapan kalimat secara langsung dan tidak langsung membawa interpretasi yang berdeba. Variasi permintaan tidak langsung memberikan ilusi yang baik, dan dianggap sopan. Pengucapan kalimat secara langsung sering dianggap kasar dan bernada memerintah serta dianggap tidaks opan.

Salah satu metode pembelajaran dikelas dengan diskusi, sering saat berdiskusi terjadi kesalahpahaman antar peserta didik atau antar kelompok diskusi. Kesalahpahaman itu terjadi karena penggunaan bahasa yang kurang santun oleh peserta didik, selain itu juga tidak teraturnya gilir wicara antara penutur dan petutur. Kalau tidak diluruskan kesalahpahaman tersebut bisa menyebabkan pertengkaran.

Muatan ilokutif dan kesantunan berbahasa saling berhubungan. Muatan ilokutifyang digunakan pada saat diskusi memengaruhi kesantunan berbahasa peserta didik. Penggunaan muatan

\footnotetext{
"Corresponding author.

E-mail addresses: dian_eka09@yahoo.com (Dian Eka Chandra Wardhana)
}

ISSN : 2579-3799 (Online) - BASINDO : Jurnal Kajian Bahasa, Sastra Indonesia, dan Pembelajarannya is licensed under Creative Commons Attribution-ShareAlike 4.0 International License (http://creativecommons.org/licenses/BY/4.0/).

74 | BASINDO : Jurnal Kajian Bahasa, Sastra Indonesia, dan Pembelajarannya 
ilokutif yang benar akan menyebabkan kesantunan, sebaliknya penggunaan muatan ilokutif yang salah, tidak representatif, direktif, komisif, ekspresif, atau deklaratif. Sesuai konteks akan menyebabkan ketidaksantunan. Berdasarkan uraian tersebut, penting untuk diteliti relasi muatan ilokutif dan kesantunan berbahasa pada wacana diskusi siswa.

\section{a. Peristiwa Tutur}

Komunikasi antara penutur dan petutur dapat berlangsung dengan baik karena peristiwa tutur. Peristiwa tutur dapat terjadi karena ada penutur, petutur dan kontekstuturan. Chaer (2004:47-50) menyatakan bahwa peristiwa tutur adalah terjadinya atau berlangsungnya interaksilinguistikdalamsatu bentuk ujaran atau lebih, yang melibatkan dua belah pihak, yaitu Pn dan Pt, dengansatu pokoktuturan,dalam waktu,tempat,dansituasi tertentu. Berdasarkan pendapattersebut, tergambarjelastentang komponen- komponen yang harus munculdalam peristiwatutur.Komponen tersebut secara langsung juga berelevansi dengan penelitian ini, khususnya dalam hal penjabarandatakonteks pembelajaran. Penutur dalam penelitianiniadalah siswadan petuturnya adalah siswa lain serta guru, tetapi dapat juga bertukar posisi ketika siswa lain atau guru yang berbicara. Koteks waktu, tempat, dan situasi dalampenelitian ini adalah di kelas dalam situasi formalpembelajaran dengan metode diskusi.

Hymes(dalam Chaer,2004:48) mengatakanbahwapercakapan baru dapat disebut sebagaiperistiwa tutur apabila memenuhi delapan komponenyang diakronimkan SPEAKING.Kedelapan komponen tersebutadalahS(Settingandscene), P (participants), E (end: Purpose andgoal),K(key:toneor spiritact), $\mathrm{I}$ (intrumentalities), N(normof interactionandinterpretation), G (genres).

\section{b. Pembelajaran Sebagai Peristiwa}

Tutur Pembelajaran di kelas termasuk dalam peristiwa tutur, karena melibatkan siswa danguruserta konteks tuturan di kelas. Selvin (dalam Brown,2007:8)menyatakan bahwapembelajaran adalah sebuah perubahan dalamdiriseseorangyang disebabkanoleh pengalaman.Sejalan denganpendapat Selvin,Brown (2007:8)berpendapat bahwa pembelajaran adalah penguasaan atau pemerolehan pengetahuan tentang suatu subjekatau sebuah keterampilan dengan belajar, pengalaman,atau konstruksi. Berdasarkan kontekstersebut, pembelajaran merupakan kegiatan yangdilakukan secarasengajadan terstruktur dengan tujuan akhir adalah penguasaan. Pembelajaran dalampenelitianinidiartikan sebagai peristiwatuturyangterjadi dan merupakan usaha dariproses perubahan tingkah laku di mana tidak bisa terlepas dari tuturan sebagai bagiandari implementasi tujuannya.

Berdasarkan kedua pendapat tersebut,dapatdisimpulkan beberapa konsep dasar, yaitu pembelajaran adalah penguasaan pengetahuan tentangsuatu subjekdengan disertai perubahandalam diri seseorang berdasarkan pengalaman.Jadi, dapat disimpulkanbahwaakhir dari pembelajaran yaitu penguasaan pengetahuan dan perubahan.Proses penguasaan pengetahuan dan perubahandiri siswaseharusnya dilakukan secaramenyeluruh dan terpadu. Penguasaan dan perubahan ini tidak terlepas dari peran siswa lainatauteman,gurudan sekolah.

Beberapaaspekyang harus diperhatikan dalam proses pembelajaran diantaranyaadalah karakteristikpebelajardan konteks sepertiyangdikemukakan Brown. Brown (2007:2) menawarkan beberapapertanyaanterkait aspek karakteristikpebelajar,yaitu siapa pebelajar,apalatarbelakang etnis, linguistik, dan keagamaan mereka, apa bahasa asli, tingkat pendidikan, dankarakteristiksosial ekonomi mereka,apakemampuan, kelemahan dan kekuatan mereka. Brown menawarkan aspek karakteristik dengan mengaitkan aspek konteks yangharusdiperhatikan dalam pembelajaran. Konteks yang ditawarkan tersebut dapat dari intrinsikpebelajarataupun ekstrinsik pebelajar.

\section{c. Tindak Tutur}

Komunikasi tidak hanya sekadar mengekspresikan pernyataan kebahasaan saja, melainkan ada suatu tindakan yang terkandung dalamsuatututuran,halinilah yang dikenal dengan sebutan speech act atautindaktutur.Yule (2006:81) menyatakan dalam menghasilkan tuturan,seseorang tidak hanya menghasilkan tuturan yang mengandungkata-katadan struktur- struktur gramatikal saja, tetapi mereka juga memperlihatkan tindakan-tindakan melalui tuturan itu.Tindaktuturlebih fokusdalam meilihat makna atau arti tindakan dalamtuturannya. Istilah tindak tutur muncul karena di dalam mengucapkan sesuatu, Pn tidak semata-mata menyatakan tuturan, akan tetapi mengandung maksudlebihdari sekadartuturan. Austindalam Sadock(2007:1) menyebutkanbahwa pada dasarnya padasaatseseorang mengatakan sesuatu,diajugamelakukan sesuatu. Pernyataan tersebutkemudian mendasari lahirnyateori tindaktutur. Yule (2006:82) mendefinisikan tindak tutur sebagai tindakantindakan yang ditampilkan lewat tuturan. 
Tindakan yang ditampilkan denganmenghasilkan suatu tuturan mengandungtigatindakyang saling berhubungan.Dalam hal ini,Austin dalam Leech (1993:316) menyebutkan ada tiga jenis tindak tutur, yaitu tindak lokusi, tindak ilokusi,dan tindakperlokusi.Sejalan dengan pendapat Leech, Searle (dalam Nadar,2009:14)membagi tindaktuturmenjadi tigamacam tindakanyangberbeda,yaitu tindak lokusioner, tindak ilokusioner,dan tindakperlokusioner.

Di antara tiga tindak tersebut yang paling penting adalah tindak Ilokusi, karena tindak ilokusi merupakan dasardaritindaklokusidan tindak perlokusi. Searle (1969:30) mengatakan bahwa bila orang menggunakantitikilokusi sebagai pengertiandasarbagi klasifikasi penggunaanbahasa,berarti orang tersebutmelakukanhal dasardalam bahasa. Tindak tutur lokusi adalah tindaktuturyangdimaksudkan untuk menyatakan sesuatu;tindak mengucapkan sesuatu dengan kata dan makna kalimat sesuai dengan makna kata itu didalamkamusdan maknakalimatitu menurutkaidah sintaksisnya (Gunarwan dalam Rustono, 1999:37). Fokus lokusi adalah makna tuturan yang diucapkan, bukan mempermasalahkan maksud atau fungsituturan itu.SedangkanYule (2006:84)mendeskripsikan tindak perlokusisebagai tindakyang ditimbulkan akibat tuturan. Berdasarkan pendapat-pendapat tersebut,dapatdisimpulkan bahwa tindakperlokusi adalahtindak ditimbulkan sebagai akibat tuturan, dantindaktersebutmuncul setelah adanyatindakilokusi.

\section{d. Muatan Ilokutif}

Yule (2006: 84) menyatakan bahwa tindak ilokusi merupakan tindakmembentuktuturan dengan beberapa fungsi di dalam pikiran. Sadock (2007:2)mengemukakan bahwa tindak ilokusi diidentifikasikansebagai tindak performatif yang eksplisit. Jadi, dapat disimpulkan bahwa tindak ilokusi adalahtindaktuturyang mengandungmaksudtersiratdi luar tuturandanberkaitandengan situasi tuturan,apayangingindicapai oleh penuturnyapadawaktu menuturkan sesuatu.

Ilokusi merupakan tindak tutur yang mengandung maksud dan fungsiatau daya tuturan. Tujuan penuturdalam bertuturbukanhanya untukmemproduksi kalimat-kalimat yangmemiliki pengertiandanacuan tertentu. Bahkan tujuannyaadalah untuk menghasilkan kalimat-kalimat yangmemberikankonstribusi jenis gerakaninteraksional tertentupada komunikasi.

Maksudyangterkandung dalam tindak ilokusi harus disimpulkan sendiri oleh petutur berdasarkan situasi tuturan. Hal tersebut dikarenakan penutur memiliki maksudlaindari tuturanyang diucapkannya. Untuk mengidentifikasi tindaklokusi,maka harus memperhatikan penutur, petutur,dansituasi tuturan.Wijana (1996:19)menyatakanbahwa dalam mengidentifikasi tindak ilokusi terlebih dahulu harus mempertimbangkan siapa penutur dan petutur, kapan dan di mana tuturanitu terjadi,dan sebagainya. Dengan demikian,tindak ilokusi merupakanbagiansentral untuk memahamitindaktutur.

Dalam perencanakankalimat, pembicarajugaharus memutuskan kontenilokutif apauntukmembuat lawantuturmengikutikeinginan dari penutur (Clark, 1977:227). Penutur memiliki duamasalahyangperlu dipecahkandalam bertutur.Pertama, tindak tutur apa yang ingin mereka pakaiuntukmenyampaikan kalimat, secaralangsung atau secaratidak langsung.Kedua,dalam bentuk bagaimana mereka harus mengungkapkannya, secara representatif, direktif, komisif, ekspresif, ataudeklaratif.

Clark dan Clark (1977:242) juga membagi muatan ilokutif menjdi lima kategori, yaitu representatif, direktif, komisif, ekspresif, dan deklaratif.Sejalandengan Clarkdan Clark, Searle (dalam Dardjowidjojo, 2012:95) membagi muatan ilokutif kedalamlimakategori,yaitu tindak ujaran representatif, tindak ujaran direktif, tindak ujaran komisif, tindakujaran ekspresif,tindak ujaran deklaratif.

1. Tindak ujaran yang berupa representatif

Searle (dalam Dardjowidjojo, 2012:95) menyatakan tindak ujaranyangberupa representatif adalah pernyataan (assertions) tentangsuatukeadaandi dunia. Pembicaraanapayang dinyatakan mengandung kebenaran.Tuturan representatif merupakan tuturan yangberfungsi menetapkanatau menjelaskanapadan bagaimana sesuatu itu adanya. Tuturan tersebut mengikat penuturnya akankebenaran tuturannya.Jadi dapatdikatakan bahwatuturan representatif seolah-olahmembuat penuturnya bertanggung jawab atas apa yangdituturkannya. Jenis tuturan yang termasuktuturan representatif adalahtuturan menyatakan,menuntut, mengakui, melaporkan, menunjukkan, menyebutkan, memberikan, bersaksi,berspekulasi.

\section{Tindak ujaran direktif}

Searle (dalam Dardjowidjojo, 2012:95) menyatakan tindak ujarandirektifadalah pembicara melakukantindakujaran dengan tujuanagarpendengar melakukan sesuatu. Jenis tuturan yang termasuktuturandirektif adalah memaksa,mangajak, meminta, menyuruh, menagih, mendesak, memohon, menyarankan, memerintah, menantang. 


\section{Tindak Ujaran komisif}

Searle (dalam Dardjowidjojo, 2012:95) mengatakan tindak ujaran komisif sama dengan tindak ujaran direktif, tetapipada ujarandirektifpendengarlah yang diharapkan melakukan sesuatu sedangkantindakujaran komisif, diarahkan padapembicarasendiri. Saat mengujarkan kalimat komisif, penutur berkomitmen dengandirinyasendiri untuk beberapa program yang akan datang dalam tindakan. Jadi tindak ujaran komisif berfungsi berkewajiban, dan bernadzar.

\section{Tindak ujaran ekspresif}

Searle (dalam Dardjowidjojo, 2012:95) mengatakan tindak ujaranekspresifdipakai oleh pembicara bila dia ingin menyatakan keadaan psikologis diamengenai sesuatu,misalnya, menyatakan rasa terima kasih, belasungkawa, menyampaikan ucapan selamat, dan juga mengumpat, mengeluh, menyalahkan, memuji, mengkritik.

\section{Tindak ujaran deklaratif}

Searle (dalam Dardjowodjojo, 2012:95) menyatakan tindak ujaran deklaratif merupakan adanyasuatukeadaan baru yang muncul oleh karena ujaran itu. Ketikapenutur mengujarkan deklaratif banyakkatapernyataan baru, yang termasuk ke dalam jenis tuturan ini adalah tuturan dengan maksud mengesankan, memutuskan, membatalkan, melarang, mengabulkan, mengizinkan, menggolongkan, mengangkat, mengampuni, memaafkan. Tindakujaran ini membutuhkan wewenang, tanpa wewenangucapan tersebuttidak akan berarti.

\section{e. Kesantunan Berbahasa}

Leech(1993:206) megemukakan teorikesantunanberdasarkan prinsip kesantunanyangdijabarkan menjadi enam maksim. Keenam maksim tersebutadalahsebagaiberikut:

\section{Maksim kearifan (TactMaxim)}

Leech (1993:209) mendefinisikan maksim kearifan denganmembuatkerugian orang lain sekecil mungkin,danmembuat keuntungan orang lain sebesar mungkin. Maksudnya, dalam bertuturseseorang akan dikatakan santun jika banyak membuat keuntunganbagi oranglaindan meminimalkan kerugiannya.

Maksim ini menggariskan bahwasetiappesertapertuturanharus meminimalkan kerugian orang lain, atau memaksimalkan keuntungan bagi orang lain. Dengan kata lain buatlah kerugian orang lain sekecil mungkin dan buatlah keuntungan oranglain sebesarmungkin.Orang bertutur yang melaksanakan maksim kearifaniniakandikatakan sebagai orangsantun. Apabila dalambertutur orangberpegang teguh pada maksim kearifan,penuturakan dapat menghindarkan sikap dengki, irihati, dan sikap-sikap lain yang kurang santun terhadap petutur. Rasa sakit hati dalampertuturanjugadapat diminimalisir denganmaksimini.

Maksim kearifan ini sama sepertimaksimkebijaksanaan yang diungkapkan oleh Rahardi. Rahardi (2005:60) mengungkapkan bahwa parapesertapertuturan hendaknya berpegang padaprinsipuntuk selalu mengurangi keuntungan dirinya sendiri dan memaksimalkan keuntungan pihak lain dalam kegiatan bertutur. Orang yang bertutur, berpegang, dan melaksanakanmaksim kebijaksanaan atau kearifan akan dikatakansebagai orangsantun.

Wijana (1996:56) menambahkan bahwa semakin panjangtuturanseseorang semakin besarpulakeinginan orang itu untuk bersikap santun kepada lawan tuturnya.Demikian tuturan yang diutarakansecara tidaklangsung lazimnyalebihsantun dibandingkan dengan tuturan yang diutarakan secaralangsung.

2. Maksim kedermawanan (GenerosityMaxim)

Maksim ini menghendaki setiap pertuturan untuk memaksimalkan kerugian bagi dirinya dan meminimalkan keuntungandiri sendiri.Leech (1993:206)mengemukakan konsep sederhana sebagai berikut: (a) buatlah keuntungan diri sendiri sekecil mungkin, (b) buatlah kerugian diri sendiri sebesar mungkin. Rahardi (2005) mengatakanbahwadengan maksim kedermawanan atau maksim kemurahan hati, para peserta pertuturandiharapkan dapat menghormatiorang lain (h.61). Penghormatan orang lainakanterjadi apabilaorangdapat mengurangi keuntunganbagidirinyasendiri dan memaksimalkan keuntungan bagi pihaklain.

\section{Maksim pujian (Approbaation Maxim)}

Maksim ini menuntut setiap peserta pertuturan untuk mengurangi cacian pada orang lain dan menambahipujian padaorang lain. Leech(1993:206) mengemukakan konsep (a) kecamlah orang lain sesedikit mungkin, dan (b) pujilah oranglain sebanyakmungkin.Tidak hanya dalam menyuruh dan menawarkansesuatu seseorang harus berlakusantun,tetapi di dalam mengungkapkan perasaan, dan 
menyatakanpendapat iatetap diwajibkan berperilaku santun (Wijana, 1996:55-60). Dengan maksim pujianini,parapeserta pertuturandiharapkan dapat menghormatioranglain.

\section{Maksim kerendahhatian (ModestyMaxim)}

Maksim ini menuntut setiap peserta pertuturan untuk memaksimalkan ketidakhormatan pada dirinya sendiri dan meminimalkan rasahormatpadadiri sendiri.Leech (1993:207) mengemukakan konsep sederhana(a) pujilah diri sendiri sedikit mungkin, (b)kecamlahdirisendiri sebanyak mungkin.

Orang akan dikatakan sombong dan congkak hati apabila di dalam kegiatanbertuturselalumemuji dan mengunggulkan dirinya sendiri. Dalam masyarakat bahasa dan budaya Indonesia, kesederhanaan dan kerendahhatian banyak digunakan sebagai parameter penilaian kesantunan seseorang.

\section{Maksim kesepakatan (AgreementMaxim)}

Maksiminimenghendaki agar penutur dan lawan tutur memaksimalkankesetujuandi antara mereka,dan meminimalkan ketidak setujuandi antaramereka.Leech (1993:207)menggemukakan konsep sederhana(a)usahakan agar ketaksepakatanantaradiri danlain terjadisedikitmungkin,dan (b) usahakan agar kesepakatan antara diri dan lain terjadi sebanyak mungkin. Apabila terjadi kemufakatan atau kecocokan di antaradiri penuturdanpetuturdalam kegiatan bertutur,masing-masing diri merekaakan dapatdikatakansantun.

\section{Maksim simpati (Simpathy Maxim)}

Maksim ini mengharuskan semuapesertapertuturan untuk memaksimalkanrasasimpati dan meminimalkanrasaantipati kepada lawan tutur.Leech(1993:207) mengemukakan konsep (a) kurangilahrasaantipati antaradiri denganorang lain hinggasekecil mungkin,(b)tingkatkan rasasimpati sebanyak-banyaknya antara diri dan lain. Sikapantipati terhadapsalah seorang pesertatuturakan dianggap sebagaitindakan tidaksopansantun (Rahardi, 2005:65). Masyarakattutur Indonesia, sangat menjunjung tinggi rasa kesimpatian terhadap orang lain didalam komunikasi kesehariannya. Orang yang bersikap antipati terhadaporanglain,apalagi sampai bersikap sinis terhadap pihak lain, akan dianggap sebagai orang yang tidaktahusopan santun.

\section{f. Koteks}

KoteksmenurutBrown (1996:46) adalah kata-kata yangdibatasidalam suatuwacana. Maksud pernyataanini adalah setiapkalimatselain kalimat pertama yang terdapat dalam wacana, seluruhtafsirannyasecara paksaakandibatasi olehteks sebelumnya, tidak hanya frase-frase yangsecarajelasmengacupada teks sebelumnya. Petutur akan lebih mudah menafsirkan apa yang dimaksudolehpenutur jikapenutur menyusunkata-kataatauteks dengan urutan yang jelas. Makin banyak adanyakoteksumumnyamakin jelas tafsirannya.

Koteks menurut Yule (2006:23) adalah bahan linguistik yang membantu memahami sebuah ekspresi atau ungkapan. Koteks bersifat sejajar, koordinatif, dan memiliki hubungan dengan teks lainnya, teks satu memiliki hubungan dengan teks lainnya. Teks lain tersebut bisa berada di depan (mendahului) ataudi belakang (mengiringi). Keberadan koteks dalamsuatu strukturwacana menunjukkan bahwatekstersebut memiliki struktur yang saling berkaitan satu dengan yang lain. Gejala inilah yang menyebabkan suatu wacana menjadiutuh dan lengkap.

\section{g. Konteks}

Keraf (1990:67) memaknai konteks sebagai lingkungan yang dimiliki olehsebuahkata.Dalam analisis wacana,konteksdan teksadalah dua komponenyangdikaji dan dideskripsikan secara bersamaan. Konteks memasukkan semua situasi dan hal yang berada di luar teks untuk mempengaruhi pemakaian bahasa, seperti partisipan dalam bahasa dan situasi di mana teks tersebut diproduksi. Secara praktis teks wacana melingkupi situasi peristiwa atau sejarah yang mengikuti wacana tersebut, seperti iklim politik, iklim sosial budaya, iklim pertahanan keamanan, religi danekonomi yangmemengaruhi penggunaanbahasa.Hal ini terjadi karenapadahakikatnya bahasaselalu berada di dalam konteks dan tidak ada tindak komunikasi tanpa partisipan,interaksi,situasi dan sebagainya.

Leech (1993:19) memerikan kontekssebagaisalah satu komponen dalam situasi tutur.Menurut Leech, konteksdidefinisikansebagai aspek- aspek yang berkaitan dengan lingkunganfisikdansosial sebuah tuturan.Leech menambahkan dalam definisinya tentang konteks yaitu sebagaisuatu pengetahuan latar belakang yang secara bersamaan dimilikioleh penuturdan petutur menafsirkan atau menginterpretasi maksudtuturanpetutur.

Kontekspenting dalam menafsirkanberbagai macam teks. Konteksmenentukan maknasuatu ujaran. Rahardi (2005:50) berpendapatbahwakonteks adalah segala latar belakang pengetahuan yang dimilikioleh penutur danlawan tuturyangmenyertaisebuahtuturan. 
Keberadaankonteks penting dalam proses komunikasi, jika penutur menyampaikan informasi dan lawan tuturtidak memahami konteksyang terdapatdalam komunikasi tersebut, maka maksud dan tujuan penutur tidak akan tersampaikan dengan baik kepada petutur.Konteksberfungsi untuk memperlancar tuturan, karena konteksmempengaruhi kemampuan petutur dalam menginterpretasikan suatututuranyang dimaksudoleh penutur.

Dari beberapa pendapat para ahli di atas dapat dilihat persamaan tentangkonteks,yaituhal-hal yang mempengaruhi prosestuturan,dapat berupa tempat, waktu, lingkungan sosialbudayapenuturdan petutur. Konteksadalahlingkungan yang memengaruhiprosestuturan.

Kesantunan berbahasa akan mengatur apa yang harus dikatakan padawaktu dan keadaan tertentu kepada lawan tutur berkenaan dengan status sosial budaya masyarakat tersebut. Realitas sosial akan berpengaruh terhadap penggunaan bahasa. Perubahan bentukkalimatsaatdigunakan dalam berkomunikasiberpengaruh terhadap nilai rasadari kalimat tersebut, disesuaikan kepadasiapapenutur berbicara(Bahardur \& Ediyono, 2018).

\section{h. Wacana Diskusi}

Kegiatan pembelajaran diperlukanmetodediskusi untuk memecahkan suatu permasalahan. Killen(dalam Dharma,2008:18) menyatakan bahwa tujuan utama metode ini adalah untuk memecahkansuatu permasalahan, menjawab pertanyaan, menambah dan memahami pengetahuan siswa, serta untuk membuat suatu keputusan. Dalam kegiatan berdiskusi diperlukancaradan pemakaianbahasayangsantun agar terjalinkomunikasiyang baikantara penuturdanpetutur.

Diskusi kelas merupakan diskusi yangdilaksanakandi kelas sebagaibagiandari aktivitas pembelajaran.Dalam pembelajaran, diskusi dapatsebagai materi pembelajarandansebagaisalah satu teknik yang dirancang dandigunakan oleh guru untukmenyajikan materi pembelajaran.Sebagai materi pembelajaran, diskusi diajarkan kepada siswa sehingga siswa tahu dan bisa berdiskusi. Sebagai salah satu teknikpembelajaran,diskusi merupakanalat untukmengajarkan materi pembelajarankepadasiswa. Dalam penelitianini yangdigunakan adalahdiskusi sebagai teknik pembelajaranbukansebagai materi pembelajaran.

\section{i. Relasi Muatan Ilokutif dan Kesantunan Berbahasa}

Rumus relasi muatan ilokutif dan kesantunan berbahasa yang digunakan dalam penelitian ini sebagai berikut: 1) Representatif santun, 2) Representatif tidak santun, 3)Direktifsantun,4)Direktif tidak santun, 5) Komisif santun, 6) Komisif tidak santun, 7) Ekpresif santun, 8) Ekspresiftidak santun, 9) Deklaratif santun, 10) Deklaratif tidaksantun.

\section{METODE}

Pendekatan yang digunakan dalampenelitianiniadalah kualitatif. Data dianalisis dengan mendeskripsikanmuatan ilokutif, kesantunan berbahasa dan relasi muatanilokutif dankesantunan berbahasa. Jenis penelitian iniadalah deskriptif.Tujuanpenelitian ini mendeskripsikan secara rinci dan dalam tentang tuturan yang mengandung muatan ilokutif,kesantunan berbahasa serta relasi muatan ilokutifdankesantunan berbahasa.

Data penelitian ini adalah ujaran yangbermuatanilokutif dan berkesantunan berbahasa yang terdapatpadawacanadiskusi siswa kelas VII. Sumber datapenelitianini adalah rekaman dari tuturan siswa kelasVIIsaatberdiskusi dalam pelajaranbahasaIndonesia.

Teknikpengumpulan datadalam penelitian ini adalah teknik simak bebas libat cakap dan rekam. Instrumen penelitian ini adalah peneliti. Perekaman dilakukan langsung oleh peneliti yang tidak terlibat dalam proses pembelajaran. Alatbantuyangdigunakan adalah handicame sebagaialat perekamdan buku sebagai catatan lapangan. Teknik analisis data dalampenelitian iniadalah teknikagih.Instrumen penganalisisan data dalam penelitian iniadalah kartu data.Analisisdata penelitian ini dilakukan melalui tiga tahapyaitu (1)menganalisismuatan ilokutif,(2)menganalisis kesantunan berbahasa,(3) menganalisisrelasi muatanilokutif bankesantunan berbahasa.

Tempatpenelitian adalah SMP Negeri1Sendang,beralamatdi Jalan RayaSendang nomor06Kabupaten Tulungagung. SMP Negeri 1

Sendang Kabupaten Tulungagung dipilih karena sekolah inimerupakan SMPpinggiran yang masih mempertahankankearifan lokal,nilai budaya, adatistiadat, dansopan santun. 
HASIL

Berdasarkan analisis data didapatkan hasil kajian sebagai berikut.

1. Muatanilokutif padawacana diskusi siswakelasVIIterdiri atasekspresif, direktif, representatif, komisif, deklaratif. Dari hasil analisis muatan ilokutif padawacanadiskusi siswakelas VIImenunjukkan dominasimuatan ilokutif ekspresif. Penggolongan proposisidikajidari bentuk apakah berpengaruh banyak atau minim. Dalam hal ini ukuran tidak ada yang mutlak, melainkan diambil dari kecenderunganatau kedominanan.

2. Kesantunanberbahasa yang ditemukan dalam penelitian iniadapenaatan dan pelanggaran. Berdasarkan analisisdata,diurutkan dari jumlah terbanyak hingga yang paling sedikit,penaatan maksim kesantunan antara lain: kearifan, kedermawanan, kesepakatan, pujian, kerendahhatian, simpati; sedangkan pelanggaran maksim kesantunan antaralain: kesepakatan, kearifan, kedermawanan, pujian, simpati, kerendahhatian.

3. Relasi muatan ilokutifdan kesantunan berbahasapada wacana diskusi siswa kelas VIImeliputi relasi muatan ilokutif santun dan relasi muatanilokutif tidaksantun. Relasi muatanilokutifsantun terdiriatasekspresif santun, meliputiekspresif pujian, ekspresif kearifan,ekspresif kerendahhatian, ekspresif kedermawanan; direktif santun,meliputi direktif kesepakatan, direktif kedermawanan, direktif kearifan;representatif santun, meliputi representatif kedermawanan, representatif kerendahhatian, representatif pujian;komisif santun, meliputi komisif kerendahhatian; deklaratif santun,meliputi deklaratif kedermawanan. Relasi muatanilokutif tidaksantun terdiriatas ekspresiftidak santun dan direktif tidak santun.

\section{PEMBAHASAN}

Hasilpenelitian menunjukkan bahwa(1)muatanilokusi ekspresif berkontradiksi dengan hakikat diskusi(2)kesantunan berbahasa terejawantahkan padawacanadiskusi siswqa; (3) relasimuatanilokutifdan kesantunanberbahasa teraktualisasi padawacanadiskusisiswa.

\section{PENUTUP}

Simpulan

Berdasarkan penganalisisan data danhasil penelitianyangdipaparkan sebelumnya,dapat ditariksimpulan berkenaan dengan relasi muatan ilokutif dan kesantunan berbahasa padawacanadiskusisiswakelas VII SMPNegeri 1SendangKabupaten Tulungagung. Simpulan dari penelitian tentang relasi muatan ilokutifdan kesantunan berbahasa, sebagaiberikut.

1. Muatan ilokutif ekspresif yang mendominasipada wacana diskusi siswakontradiktif denganhakikat diskusi. Artinya, pada wacana diskusi seharusnyalebih menggunakan fikiran yang logis yangberhubungan dengan materi pembelajaran.Akantetapi pada wacanadiskusi siswakelasVII ditemukan lebih menonjolnya ungkapan perasaan dibanding berfikir logis. Akibatnya tidak tercipta suasana diskusi yang ilmiah,melainkan hanyaajang ungkapan perasaan yang meninggikan maupun menjatuhkan kelompok lain, seharusnya diskusi lebih menonjolkan logika agar keilmiahanhasildiskusi bisa dipertanggungjawabkan.

2. wacana diskusi siswa kelas VII mengejawantahkan prinsip kesantunan berbahasa. Dibuktikan dengandatapenaatan maksim kesantunan lebih banyak dibanding maksim ketidaksantunan.Ituartinya siswa kelasVIIsaat berdiskusi menggunakan bahasa yang santun,menerapkan prinsip kesantunan berbahasa Leech sesuai teori padabab2.Lebih menonjolnya kesantunan dibanding ketidaksantunan disebabkanolehkearifan lokal. Tingginya kearifan lokaldidaerah Tulungagungkhususnya Sendang memanifestasi terjadinya kesantunan.Masyarakat masih menjunjung tinggi tata krama dan nilai moral. Selain itu, SMP Negeri 1 Sendang juga berlokasi dipedesaan sehinggamasih kental dengan adat istiadat masyarakat Jawa yang syarat akan sopan santun. Dapat disimpulkan wacana diskusi siswa kelas VII SMP Negeri 1 Sendang menerapkanprinsip kesantunan.

3. relasi muatan ilokutif dan kesantunan berbahasa teraktualisasi padawacanadiskusi siswa. Terbukti antara muatan iloktif dan kesantunan berbahasa ada relasi, baik relasisantun maupunrelasi tidaksantun. Berdasarkananalisis datamuatan ilokutif santunlebihbanyak ditemukan daripada muatan ilokutif tidak santun. Sehingga bisa dikatakan pembelajaran diskusi di kelas VII dianggap santun.Jadi,dapat disimpulkan wacana diskusi siswa kelas VII masihmenonjolkan perasaan sehingga membuat diskusi menjadisantun. 


\section{Saran}

Berdasarkan hasil penelitian dan diskusihasiltemuan,saran yang diberikan adalah sebagaiberikut. (1) Saran ditujukan kepada peneliti lain agarmengadakan penelitian lanjutan yangberkaitandenganrelasi muatan ilokutif dan kesantunan berbahasa. (2)Gurudisarankan memerhatikan normakesantunan ketikamelakukan diskusi kelas seperti memberikan pujian kepadasiswaketikaberhasil menjawabpertanyaanguru atau ungkapan rasa kagum pada siswa jika hal tersebut layak siswa dapatkan sehingga dapat menumbuhkan minatbelajarsiswa secara berulang. (3) Siswa harus dilatih untukmenggunakan muatan ilokutif yang betul agar sesuai dengankonteks.(4)Saran terakhir ditujukankepada pengembang pendidikan bahasa. Hasil penelitian ini dapatdimanfaatkanuntuk mengembangkan materibahanajar.

\section{DAFTAR RUJUKAN}

Bahardur, I., \& Ediyono, S. (2018). Unsur-Unsur Ekologi Dalam Sastra Lisan Mantra Pengobatan Sakit Gigi Masyarakat Kelurahan Kuranji. Basindo: Jurnal Kajian Bahasa, Sastra Indonesia, Dan Pembelajarannya, 1(2), 24-30.

Brown,PdanS.C.Levinson.(1978). Universalsin languageusage: Politeness Phenomena. In

E.N.Goody (ed).Questions and politeness: Strategiesin socialinteraction, 56-289. Cambridge: Cambridge University Press.

Brown,Gillian dan GeorgeYule (diindonesiakan oleh Soetikno).(1996). Analisis wacana.Jakarta: Gramedia PustakaUtama

Brown, H. Douglas. (2007).Prinsip pembejajaran dan pengajaranbahasa. Jakarta: Kedutaan Besar Amerika Serikatdijakarta.

Chaer,Abdul.(2004). Sosiolinguistik perkenalan awal. Jakarta: RinekaCipta

Chaer, Abdul. (2010).Kesantunan berbahasa.Jakarta: Rineka Cipta

Clark, H.H. dan Clark, E.V. (1977).Psychology and language: an introduction to psycholinguistics. San Diego: Harcourt Brace Jovanovich Publishers.

Dardjowidjojo, Soenjono. (2012). Psikolinguistik: pengantar pemahaman bahasa manusia. DKI Jakarta: Yayasan Pustaka Obor Indonesia.

Leech,Geoffrey. (1993).Prinsip- prinssip pragmatik. Jakarta: Universitas Indonesia.

Nadar, F.X. (2009). Pragmatikdan penelitian pragmatik. Yogyakarta:Grahallmu.

Rahardi, Kunjana. (2005). Pragmatik: kesantunan imperatif bahasa. Jakarta: Gramedia Pustaka Utama.

Rustono. (1999).Pokok-pokok pragmatik. Semarang: IKIP SemarangPress.

Sadock,Jerrold. (2007). Speech act theory: the handbook of pragmatics. Blackwell ReferenceOnline

Sudaryanto. (2015). Metodedan aneka teknik analisis bahasa. Yogyakarta: DutaWacana University Press.

Searle,J.R.(1969).Speechacts: an essayinthephilosophy of language. Cambridge: CambridgeUniversity Press.

Wijana,I.D.P. (1996).Dasar-dasar pragmatik. Yogyakarta: Andi Offset.

Yule, George. (2006). Pragmatik. Yogyakarta: Pustaka Pelajar. 